\title{
Triphalangeal thumb-polysyndactyly syndrome
}

INSERM

\section{Source}

INSERM. (1999). Orphanet: an online rare disease and orphan drug data base.

Triphalangeal thumb-polysyndactyly syndrome. ORPHA:2950

Triphalang eal thumb-polysyndactyly syndrome (TPT-PS) is a hand-foot malformation characterized by triphalangeal thumbs and pre- and postaxial polydactyly, isolated syndactyly or complex polysyndactyly. 